\title{
Karyometric comparison of splenic and gastric marginal zone lymphomas
}

\author{
Magdalena Styczeń, Joanna Szpor, Sergiusz Demczuk and Krzysztof Okoń* \\ Department of Clinical and Experimental Pathomorphology, Collegium Medicum, Jagiellonian University, \\ Kraków, Poland
}

Received: June 14, 2011

Accepted: April 25, 2012

\begin{abstract}
Background: Marginal zone lymphomas are indolent B-cell lymphomas associated with autoimmunity and chronic inflammation. The two most frequent variants are mucosa associated lymphoid tissues marginal zone lymphomas and splenic marginal zone lymphomas. The aim of the study was to determine if it is possible to classify splenic and gastric lymphomas according to karyometric features.

Methods: The material consisted of 16 splenic and 14 gastric lymphomas. The measurements were done with the AnalySIS image analysis system. In each case at least 100 nuclei were selected, and 19 different geometric parameters were measured.

Results: On statistical analysis, the nuclei of splenic and gastric lymphomas showed differences in most parameters, but significant overlap of the values was present. Neural networks were trained and used for classification of the data. By this method, the nuclei were properly classified with a sensitivity of 0.75 and specificity of 0.71 . In addition, in all the cases the majority of the nuclei were properly classified, thus allowing correct classification of all the cases into "splenic" or "gastric".

Conclusion: These results support the view that mucosa-associated lymphoid tissue lymphomas and splenic marginal-zone lymphomas are separate entities.
\end{abstract}

Keywords: Marginal zone lymphoma, image analysis, karyometry, neural network, classification

\section{Introduction}

Marginal zone lymphomas are indolent B-cell peripheral lymphomas that comprise three distinct clinicopathological entities: extranodal marginal zone lymphomas of mucosa-associated lymphoid tissues, splenic marginal zone lymphomas and nodal marginal zone lymphomas. In the current classification of the World Health Organization these are considered separate entities. However they share some common features. These features include a similar cytological composition and a tendency to run an indolent clinical course. A significant relationship was shown between a chronic inflammatory process and autoimmunity. In total these lymphomas constitute about $6 \%$ of nonHodgkin lymphomas [1-4].

${ }^{*}$ Corresponding author: Krzysztof Okoń, ul. Grzegórzecka 16, Kraków 31-531, Poland. Tel.: +48 12 6199612; Fax: +48 12 4119725; E-mail: mpokon@cyf-kr.edu.pl.
The aim of the study was to find quantitative differences between the two most frequent types of marginal zone lymphomas, gastric MALT type and primary splenic lymphomas, and to test the feasibility of an automatic classification based on karyometric features.

\section{Material and methods}

The material consisted of specimens of splenic marginal zone lymphomas and gastric MALT-type marginal zone lymphomas acquired from the files of the Department of Pathology in the years 2005-2009. The specimens have been routinely formalin-fixed and paraffin embedded. From the paraffin blocks $3 \mu \mathrm{m}$ sections were prepared and stained by a routine hematoxylin-eosin method. The images were collected and analyzed with an AnalySIS image analysis 
system, which consists of the following: an Axioscope microscope (Zeiss GmbH, Germany) with a $100 \times$ PlanNeoFluar lens, CCD camera ZVS-47DE (Optronics, USA) connected by a RGB line to a GraBIT PCI (Soft Imaging Systems GmbH, Germany) framegrabber card installed on a standard PC running AnalySIS 3.2 pro software (Soft Imaging Systems GmbH, Germany) and custom made programs prepared by one of the authors (K. O.). Well preserved fields of view were selected, and the contours of the lymphoma nuclei were traced interactively by one of the authors (M. S.), who was blinded to the site of the lesion. Care was taken to choose only the lymphoma cells. The computer system measured a set of geometric parameters (Table 1), and the results, together with the case number, were recorded to a text file. These measurements were continued until the parameters of at least 100 nuclei per case were obtained. The results were analyzed with Statistica 9.0 software (Statsoft Inc., USA). The significance level was set to $p=0.05$. The shape factor was defined as:

$$
\text { Shapefactor }=4 \pi \frac{S}{L^{2}}
$$

and compactness as:

$$
\text { compactness }=\frac{D_{\min }}{D_{\max }}
$$

Where

$S$ - area,

$L$ - perimeter,

$D_{\text {min }}$ - minimum diameter,

$D_{\text {max }}$ - maximum diameter.
Table 1

List of the parameters used in the study

Area

Minimum diameter

Mean diameter

Maximum diameter

Perimeter

Convex area

Convex perimeter

Shape factor

Equivalent circle diameter

Minimum feret diameter

Mean feret diameter

Maximum feret diameter

Minimum encosing rectagle area

Maximum encosing rectagle area

Mean encosing rectagle area

Minimum martin radius

Mean martin radius

Maximum martin radius

Convexity

\section{Results}

The material under study consisted of 30 cases, which included 12 females and 18 males. The mean age of these patients was 64.5 years, (range 28 to 84 , SD 14.4). There were 16 splenic and 14 gastric lymphomas (Fig. 1). The relative overrepresentation of splenic lymphomas was due to the fact that many of the gastric lymphoma cases consisted of small biopsies, that were often unsuitable for quantitative analysis. Also, many cases in our files consisted of consultation cases with poor access to original tissue blocks. For splenic lymphomas, the mean age of the patients was 65.1 and the female to male ratio was $7: 9$. For gastric lymphomas, the mean age of the patients was 63.9 and the female
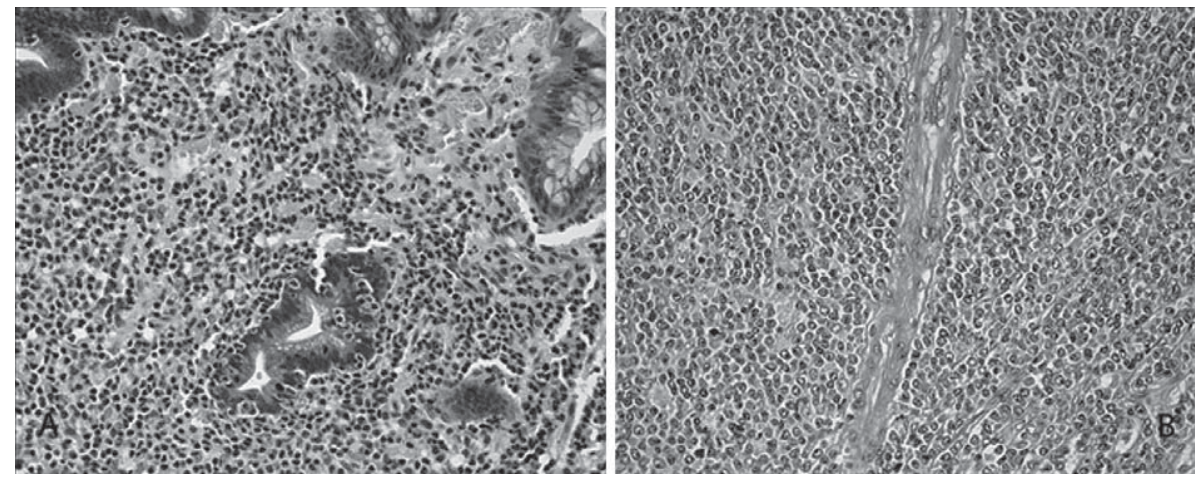

Fig. 1. Examples of gastric (A) and splenic (B) marginal zone lymphoma. Hematoxylin - eosin, original magnification $200 \times$. 
Table 2

The values of the geometric nuclear parameters

\begin{tabular}{|c|c|c|c|c|c|c|c|}
\hline & \multicolumn{2}{|c|}{ All cases } & \multicolumn{2}{|c|}{ Splenic } & \multicolumn{2}{|c|}{ Gastric } & \\
\hline & Mean & SD & Mean & SD & Mean & SD & \\
\hline Area & 16.08 & 4.96 & 16.65 & 4.23 & 15.48 & 5.57 & $p<0.01$ \\
\hline Minimum diameter & 4.09 & 0.7 & 4.27 & 0.58 & 3.9 & 0.76 & $p<0.01$ \\
\hline Mean diameter & 4.82 & 0.82 & 4.87 & 0.67 & 4.76 & 0.95 & $p<0.01$ \\
\hline Maximum diameter & 5.28 & 0.97 & 5.28 & 0.79 & 5.27 & 1.12 & $p=0.8$ (N.S.) \\
\hline Perimeter & 15.11 & 2.98 & 15.47 & 2.58 & 14.73 & 3.31 & $p<0.01$ \\
\hline Convex area & 16.84 & 5.39 & 17.45 & 4.51 & 16.19 & 6.12 & $p<0.01$ \\
\hline Convex perimeter & 14.95 & 2.5 & 15.2 & 2.07 & 14.68 & 2.86 & $p<0.01$ \\
\hline Compactness & 0.78 & 0.1 & 0.81 & 0.08 & 0.75 & 0.11 & $p<0.01$ \\
\hline Shape factor & 0.89 & 0.13 & 0.88 & 0.14 & 0.89 & 0.12 & $p<0.012$ \\
\hline Equivalent circle diameter & 4.47 & 0.67 & 4.57 & 0.57 & 4.38 & 0.75 & $p<0.01$ \\
\hline Minimum feret diameter & 4.08 & 0.67 & 4.24 & 0.56 & 3.91 & 0.73 & $p<0.01$ \\
\hline Mean feret diameter & 5.31 & 0.97 & 5.32 & 0.8 & 5.3 & 1.12 & $p=0.53$ (N.S.) \\
\hline Maximum feret diameter & 4.76 & 0.76 & 4.84 & 0.63 & 4.68 & 0.87 & $p<0.01$ \\
\hline Minimum encosing rectagle area & 21.04 & 6.66 & 21.65 & 5.57 & 20.39 & 7.59 & $p<0.01$ \\
\hline Mean encosing rectagle area & 23.04 & 7.59 & 23.67 & 6.26 & 22.36 & 8.73 & $p<0.01$ \\
\hline Maximum encosing rectagle area & 24.41 & 8.35 & 25.03 & 6.9 & 23.75 & 9.62 & $p<0.01$ \\
\hline Minimum martin radius & 1.77 & 0.32 & 1.85 & 0.28 & 1.68 & 0.34 & $p<0.01$ \\
\hline Mean martin radius & 2.18 & 0.34 & 2.24 & 0.29 & 2.12 & 0.38 & $p<0.01$ \\
\hline Maximum martin radius & 2.67 & 0.48 & 2.67 & 0.4 & 2.67 & 0.56 & $p=0.96$ (N.S.) \\
\hline Convexity & 0.96 & 0.03 & 0.96 & 0.03 & 0.96 & 0.03 & $p<0.01$ \\
\hline
\end{tabular}

$p$ values by ANOVA test. SD - standard deviation. N.S. - non-significant.

to male ratio was $5: 9$. The differences between these groups were not statistically significant.

There were statistically significant differences between the group under study for the large majority of the parameters (Table 2, Fig. 2). These differences were seen in both the t-Student test and in nested ANOVA, which showed differences between the individual cases and also between the two groups under study. The only parameters that did not differ between splenic and gastric lymphomas were maximum diameter, maximum Feret diameter and maximum Martin radius.

Classification of the individual nuclei was attempted using neural networks. The dataset was randomized into a training set, a validating set and a testing set. The results of the classification of the individual nuclei by the best network (1-hidden layer) are shown in Table 3 . A majority of nuclei are properly classified. However, far more interesting is the proper classification of cases. For this purpose, the number of nuclei assigned to the "spleen" or "stomach" was compared for all the lymphomas under study. The proportion of nuclei classified as "splenic" to the ones classified as "gastric" was 3.12 (range 0.14 to 31.0 , SD 5.82) in the entire dataset, 5.42 (range 1.20 to 31.0 , SD 7.30) for splenic lymphomas, and 0.47 (range 0.14 to 0.95 , SD 0.28 ) for gastric lymphomas (Table 4). As a consequence, the majority of nuclei were properly classified in all cases, allowing for classification of the entire case.

\section{Discussion}

In our work, we analyzed the geometric parameters of the nuclei of two closely related variants of non-Hodgkin lymphomas. Although these variants of marginal zone lymphomas are currently regarded as separate entities, they largely share cytological features. Despite simple methodology, classification of the data by a neural network allowed proper classification of the cases.

MALT lymphomas are by far the most common of the marginal zone lymphomas, comprising as much as $8 \%$ of all B-cell lymphomas, while their most frequent location is the stomach $(85 \%)$ or other parts of the gastrointestinal tract, MALT lymphomas may also be found outside the gastrointestinal tract, specifically in the lung, head and neck region, thyroid, skin, or breast. Etiologically, the MALT lymphomas are related to chronic inflammation and autoimmune disease. Gastric lymphomas are seen mainly in Helicobacter pylori infected patients. However, less than $0.1 \%$ of infected individuals develop lymphoma [5]. In other sites the 

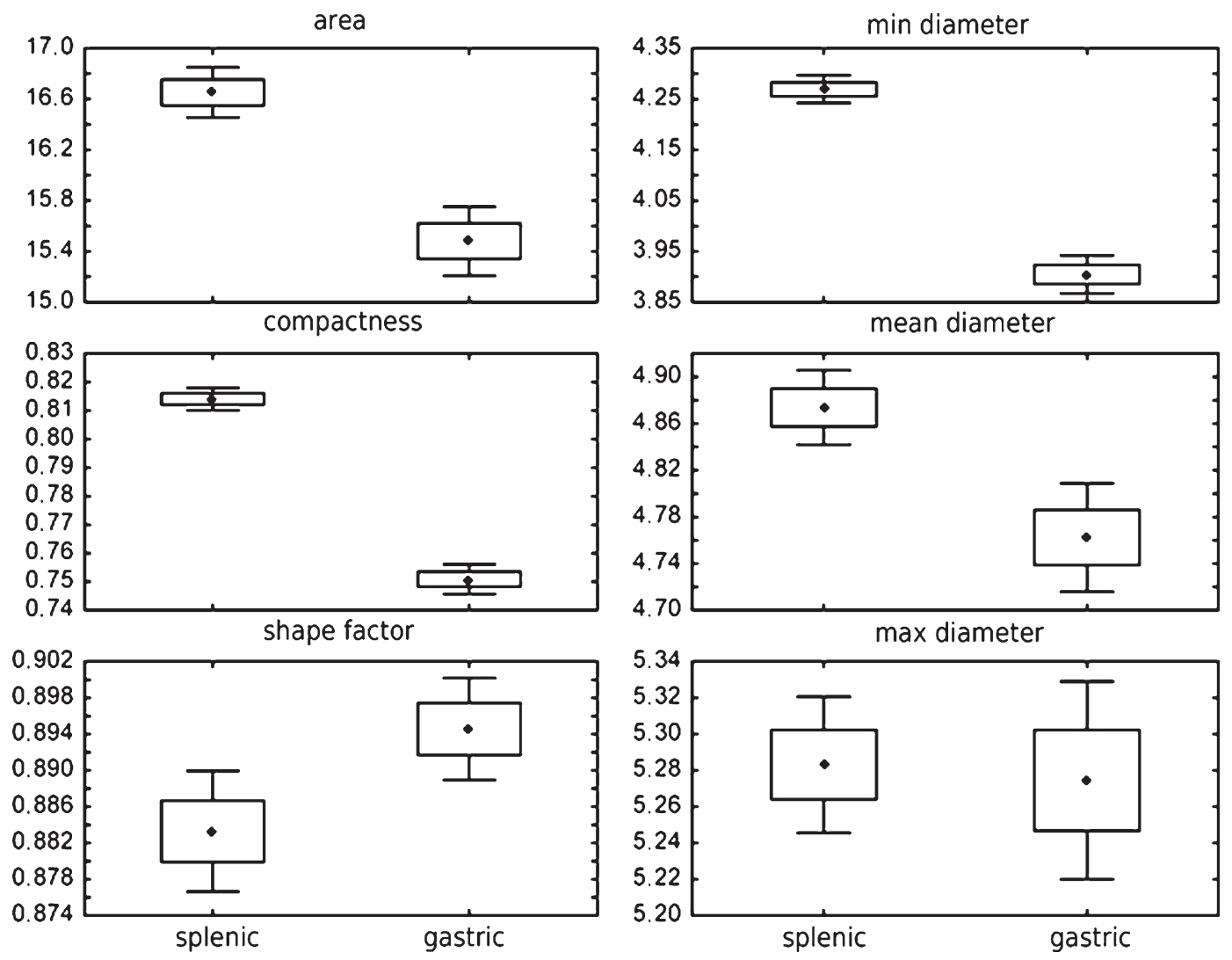

Fig. 2. Basic geometric nuclear parameters. Central point is mean, box indicates mean \pm standard error, whiskers mean \pm standard deviation.

putative etiological factors include Chlamydia psittaci, Campylobacter jejuni, and Borrelia burgdorferi. Eradication of the infectious agent may induce remission of the lymphoma, However, later in the disease course the neoplastic phenotype becomes independent of inflammatory stimulation [5-7]. The karyotypic alterations in MALT lymphomas are various, although they seem to be related to the activation of the nuclear factor kappa B (NF- $\mathrm{B}$ ) pathway [8]. In the thyroid and salivary glands MALT lymphomas are related to autoimmune disorders, such as Hashimoto thyroiditis and Sjoegren disease. MALT lymphomas have an indolent nature; recurrences, that can occur after many years, may involve other extranodal sites and occur more often in patients with extragastric MALT lymphomas than in patients with primary gastric disease. The tumors are sensitive to radiation therapy, and local treatment may be followed by prolonged disease-free intervals [3].

Despite the common term "marginal zone lymphoma", clinical, immunophonotypic and genetic features indicate that splenic marginal zone lymphoma is an entity unrelated to MALT or nodal marginal zone lymphomas. Splenic marginal zone lymphoma is a rare disorder (1-3\% of lymphomas) that involves the spleen along with the bone marrow and peripheral blood. If present in the blood, cancer cells assume the form of villous lymphocytes. The principal symptom is splenomegaly, which may be occasionally accompanied by autoimmune thrombocytopenia or anemia. The spleen shows infiltrates composed of small lymphocytes which surround and replace the splenic white pulp germinal centers. An association with hepatitis C virus has been described, at least in Southern European patients; in these patients antiviral treatment has been beneficial. Other patients may be treated by splenectomy or chemotherapy. The clinical course is indolent, and 5-year survival varies from 65 to $78 \%$ [2, 7, 9-13].

Nodal marginal zone lymphoma is even less frequent and represents a B cell malignancy with a morphology and phenotype similar to extranodal or splenic marginal zone lymphoma, but without involvement of 
Table 3

The results of the classification of the individual nuclei by the neural network. Only the nuclei not used for network training were included

\begin{tabular}{lccr}
\hline Expected & $\begin{array}{c}\text { Obtained } \\
\text { spleen }\end{array}$ & Stomach & Total \\
\hline Spleen & 364 & 150 & 514 \\
Stomach & 123 & 363 & 486 \\
Total & 487 & 513 & 1000 \\
Sensitivity & 0.75 & & \\
Specificity & 0.71 & & \\
\hline
\end{tabular}

\section{Table 4}

Ratio of the number of nuclei classified as "splenic" or "gastric" by the neural network and the true location of the lymphomas

\begin{tabular}{|c|c|c|}
\hline Case & Location & Splenic/gastric \\
\hline 1 & Spleen & 4.2 \\
\hline 2 & Spleen & 10.7 \\
\hline 3 & Spleen & 1.2 \\
\hline 4 & Spleen & 3.0 \\
\hline 5 & Spleen & 3.1 \\
\hline 6 & Spleen & 4.3 \\
\hline 7 & Spleen & 8.3 \\
\hline 8 & Spleen & 1.7 \\
\hline 9 & Spleen & 2.1 \\
\hline 10 & Spleen & 31.0 \\
\hline 11 & Spleen & 3.5 \\
\hline 12 & Spleen & 2.7 \\
\hline 13 & Spleen & 5.8 \\
\hline 14 & Spleen & 1.3 \\
\hline 15 & Spleen & 2.1 \\
\hline 16 & Spleen & 1.7 \\
\hline 17 & Stomach & 0.9 \\
\hline 18 & Stomach & 0.4 \\
\hline 19 & Stomach & 0.6 \\
\hline 21 & Stomach & 0.1 \\
\hline 22 & Stomach & 0.2 \\
\hline 23 & Stomach & 0.6 \\
\hline 24 & Stomach & 0.5 \\
\hline 25 & Stomach & 0.8 \\
\hline 26 & Stomach & 0.3 \\
\hline 27 & Stomach & 0.2 \\
\hline 28 & Stomach & 0.3 \\
\hline 29 & Stomach & 0.9 \\
\hline 30 & Stomach & 0.6 \\
\hline
\end{tabular}

the spleen or MALT locations. In some cases in addition to peripheral lymph nodes, the bone marrow and peripheral blood may be involved. Some authors report frequent hepatitis $\mathrm{C}$ infection in these patients [4].

Despite immunophenotyping and molecular analysis becoming necessary for diagnosis of lymphomas, assessment of morphology remains the basic and indispensable method. Image analysis is aimed to make the morphology assessment more objective and to gain features that are hidden to the pathologist. Image analysis is able to extract dozens of features describing the structures of the tissue, and classification methods may transform these features into useful information. A recurrent problem in applying this quantitative approach to pathology exists. The parameters we extract show differences between groups. However, an overlapping still exists, making the classification difficult. A multiparameter approach may be useful in such cases. In particular, neural networks are able to perform non-supervised classification of a multidimensional dataset.

Marchevsky et al. [14] were able to successfully classify a set of lymphomas with a simple computer system, which aimed to randomly select the cells and collect the results. However, the bulk of the work, in fact the classification of the cells themselves, was done by a human operator. Many T-cell lymphomas of the skin are composed of cerebriform cells; these have characteristic nuclei with extensive indentation of the nuclear membrane. Cells with a similar morphology may be present in inflammatory dermatoses. However quantitative methods show that malignant and benign cerebriform cells do differ in the degree of nuclear membrane indentation. This feature was used in quantitative analysis. Nuclear contour index (NCI) became a standard parameter for their recognition [15-18]. $\mathrm{NCI}$ is defined as the perimeter divided by the square root of the area. It is thus analogous to the standard shape factor used in the present investigation, in fact $\mathrm{SF}=4 \pi / \mathrm{NCI}^{2}$. Using this single parameter, Preesman et al. [17] were able to discriminate the circulating Sézary cells and used this method for distinguishing actinic reticulosis from Sézary syndrome. On the other hand Meijer et al. [16] failed to recognize 1/3 of mycosis fungoides cases by NCI only; using multiparameter approach allowed them to recognize all the malignant cases properly.

Quantitative analysis may be coupled with immunohistochemistry; such an approach was used previously with CD20 stain for hairy cell leukemia [19] or with CD3 stain for mycosis fungoides [20]. However, Clarke et al. [21] measured features of proliferating (PCNA+) cells only.

Fine needle aspiration biopsy is often thought to be of limited value for lymphoma diagnosis. However the material is easy to obtain by this method. Gupta et al. [22] tried to classify lymphoma smears using advanced image analysis. Both geometric and texture-based 
features were used. They report high performance of classification of individual cells, exceeding $80 \%$ if all the parameters were taken into account. However, the procedure was much less effective with cell size and shape parameters only. In our investigation, with a neural network classifier, we obtained slightly worse results on the individual nuclei. On the other hand Gupta et al. did not try to obtain classification of the cases under study, that is probably of the most imminent practical interest.

In conclusion we were able to show that gastric MALT-type and splenic mantle cell lymphomas may be separated by a neural network using only geometric parameters of the nuclei.

\section{Acknowledgment}

We thank Mrs. Teresa Chmielowiec and Mr. Michael Kozlowski for manuscript editing.

\section{References}

[1] K. Gałazka, J. Szpor, R. Maryniak, W. Olszewski, O. Mioduszewska and J. Stachura, Incidence of lymphomas in Poland. The national register data for 2006, Pol J Pathol 58 (2007), 199-206.

[2] P.G. Isaacson, C. Thieblemont, M.A. Piris, S. Pittaluga, F. Berger, N.L. Harris and S.H. Swerdlow, Splenic marginal zone lymphoma, In: WHO Classification of Tumours of Haematopoietic and Lymphoid Tissues. Ed. by S.H. Swerdlow, E. Campo, N. Lee Harris, E.S. Jaffe, S.A. Pileri, H. Stein, J. Thiele, J.W. Vardiman (IARCpress, 2008) pp. 185-187.

[3] P.G. Isaacson, A. Chott, S. Nakamura, H.K. MullerHermelink, N.L. Harris and S.H. Swerdlow, Extranodal marginal zone lymphoma of mucosa-associated lymphoid tissue (MALT lymphoma), In: WHO Classification of Tumours of Haematopoietic and Lymphoid Tissues. Ed. by S.H. Swerdlow, E. Campo, N. Lee Harris, E.S. Jaffe, S.A. Pileri, H. Stein, J. Thiele, J.W. Vardiman (IARCpress, 2008) pp. 214-217.

[4] E. Campo, S.A. Pileri, E.S. Jaffe, H.K. Muller-Hermelink and B.N. Nathwani, Nodal marginal zone lymphoma, in:WHO Classification of Tumours of Haematopoietic and Lymphoid Tissues. Ed. by S.H. Swerdlow, E. Campo, N. Lee Harris, E.S. Jaffe, S.A. Pileri, H. Stein, J. Thiele, J.W. Vardiman (IARCpress, 2008) pp. 185-187.

[5] H. Suzuki, T. Hibi and B.J. Marshall, Helicobacter pylori: Present status and future prospects in Japan, $J$ Gastroenterol 42 (2007), 1-15.

[6] K. Gałazka and J. Stachura, Factors associated with progression of primary gastric marginal zone B-cell lymphomas of mucosa-associated lymphoid tissue (MALT type), Pol J Pathol 51 (2000), 115-125.

[7] F. Suarez, O. Lortholary, O. Hermine and M. Lecuit, Infectionassociated lymphomas derived from marginal zone B cells: A model of antigen-driven lymphoproliferation, Blood 107 (2006), 3034-3044.

[8] P. Farinha and R.D. Gascoyne, Molecular pathogenesis of mucosa-associated lymphoid tissue lymphoma, J Clin Oncol 23 (2005), 6370-6378.

[9] V. Franco, A.M. Florena and E. Iannitto, Splenic marginal zone lymphoma, Blood 101 (2003), 2464-2472.

[10] W. Jurczak, Z. Rudzki, K. Gałazka, A. Gruchała, A. JaszczGruchała, A.B. Skotnicki and J. Stachura, High prevalence of non-Hodgkin's lymphomas in Polish population-1106 new cases diagnosed according to WHO classification in only one district, Pol J Pathol 57 (2006), 45-52.

[11] R.K. Maryniak and M. Prochorec-Sobieszek, Primary splenic B-cell lymphoma (marginal zone lymphoma). Clinicopathological evaluation of 10 cases, Pol J Pathol 51 (2000), $185-190$.

[12] E. Matutes, D. Oscier, C. Montalban, F. Berger, E. CalletBauchu, A. Dogan, P. Felman, V. Franco, E. Iannitto, M. Mollejo, T. Papadaki, E.D. Remstein, A. Salar, F. Solé, K. Stamatopoulos and C. Thieblemont, A. Traverse-Glehen, A. Wotherspoon, B. Coiffier and M.A. Piris, Splenic marginal zone lymphoma proposals for a revision of diagnostic, staging and therapeutic criteria, Leukemia 22 (2008), 487-495.

[13] C. Thieblemont, P. Felman, E. Callet-Bauchu, A. TraverseGlehen, G. Salles, F. Berger and B. Coiffier, Splenic marginalzone lymphoma: A distinct clinical and pathological entity, Lancet Oncol 4 (2003), 95-103.

[14] A. Marchevsky, J. Gil and D. Silage, Computerized interactive morphometry as a potentially useful tool for the classification of non-Hodgkin's lymphomas, Cancer 57 (1986), 1544-1549.

[15] N.S. McNutt and W.R. Crain, Quantitative electron microscopic comparison of lymphocyte nuclear contours in mycosis fungoides and in benign infiltrates in skin, Cancer 47 (1981), 698-709.

[16] C.J. Meijer, E.M. van der Loo, W.A. van Vloten, E.A. van der Velde, E. Scheffer and C.J. Cornelisse, Early diagnosis of mycosis fungoides and Sézary's syndrome by morphometric analysis of lymphoid cells in the skin, Cancer 45 (1980), 2864-2871.

[17] A.H. Preesman, S.J. Schrooyen, J. Toonstra, S.C. van der Putte, L.H. Rademakers, R. Willemze and W.A. van Vloten, The diagnostic value of morphometry on blood lymphocytes in erythrodermic actinic reticuloid, Arch Dermatol 131 (1995), 1298-1303.

[18] U. Reinhold, M. Herpertz, S. Kukel, I. Oltermann, M. Uerlich, H.W. Kreysel, Induction of nuclear contour irregularity during T-cell activation via the T-cell receptor/CD3 complex and CD2 antigens in the presence of phorbol esters, Blood 83 (1994), 703-706.

[19] K. Okon, A. Szumera, B. Papla, I. Pietkun, A. Zdunczyk, M. Rucinska, A.B. Skotnicki and J. Stachura, Morphometric classification of hairy cell leukemia in bone marrow trephine biopsy, Anal Quant Cytol Histol 25 (2003), 227-234.

[20] M. Lira, A.A. Schenka, L.A. Magna, A.C. Cotta, M.L. Cintra, E.M. de Souza, P. Brousset and J. Vassallo, Diagnostic value of 
combining immunostaining for $\mathrm{CD} 3$ and nuclear morphometry in mycosis fungoides, J Clin Pathol 61 (2008), 209-212.

[21] A.M. Clarke, W.A. Reid and A.S. Jack, Combined proliferating cell nuclear antigen and morphometric analysis in the diagnosis of cutaneous lymphoid infiltrates, J Clin Pathol 46 (1993), 129-134.
[22] S. Gupta, R. Gupta, S. Singh, K. Gupta and M. Kudesia, Nuclear morphometry and texture analysis of B-cell nonHodgkin lymphoma: Utility in subclassification on cytosmears, Diagn Cytopathol 38 (2010), 94-103. 


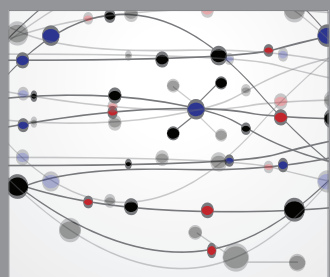

The Scientific World Journal
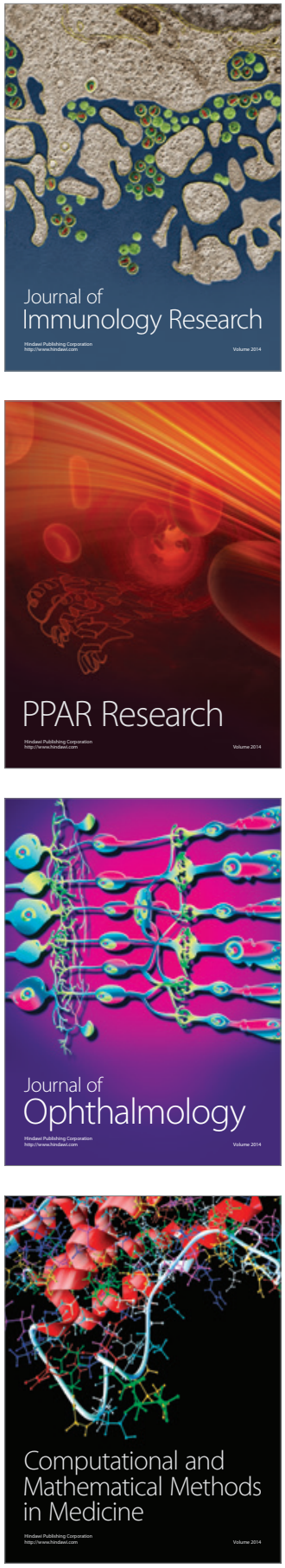

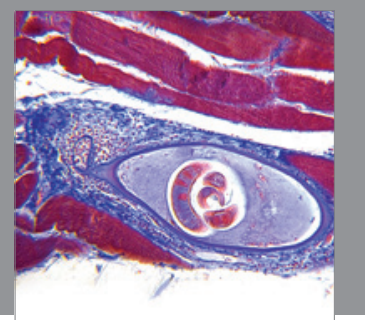

Gastroenterology

Research and Practice
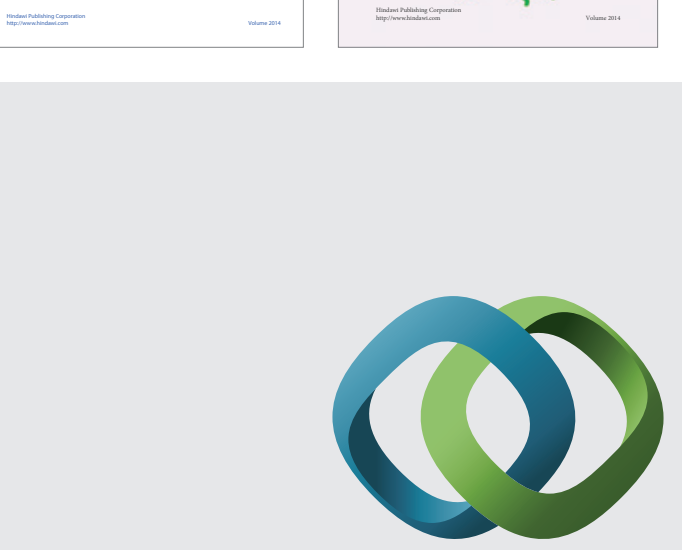

\section{Hindawi}

Submit your manuscripts at

http://www.hindawi.com
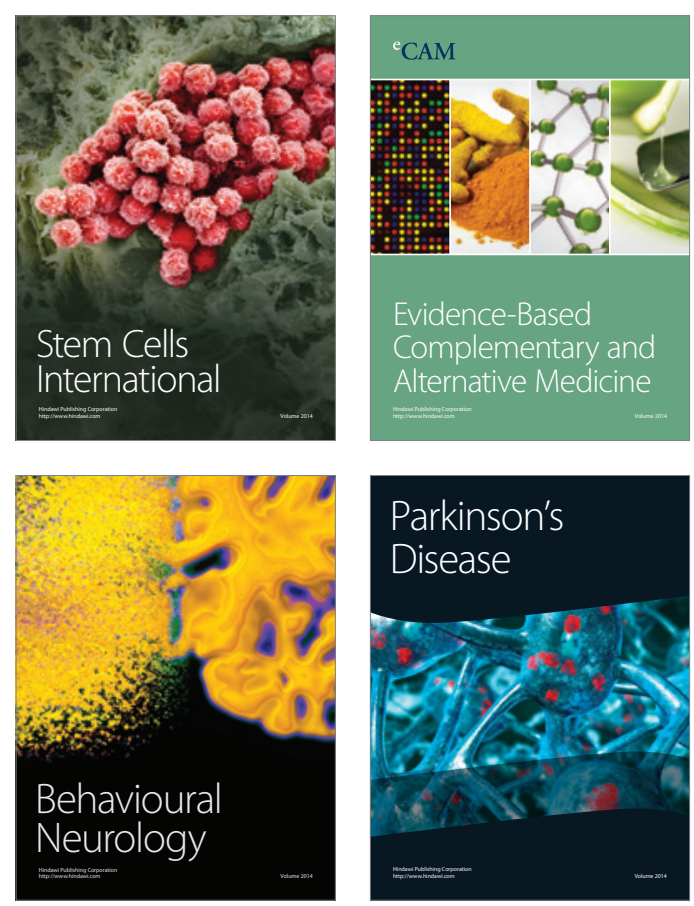

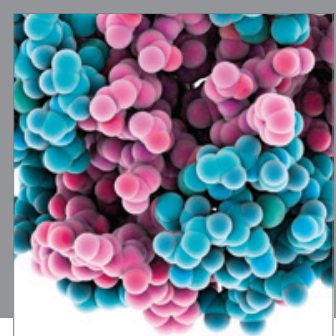

Journal of
Diabetes Research

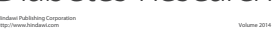

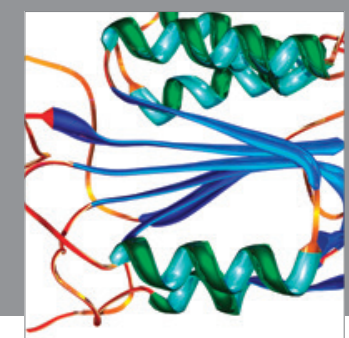

Disease Markers
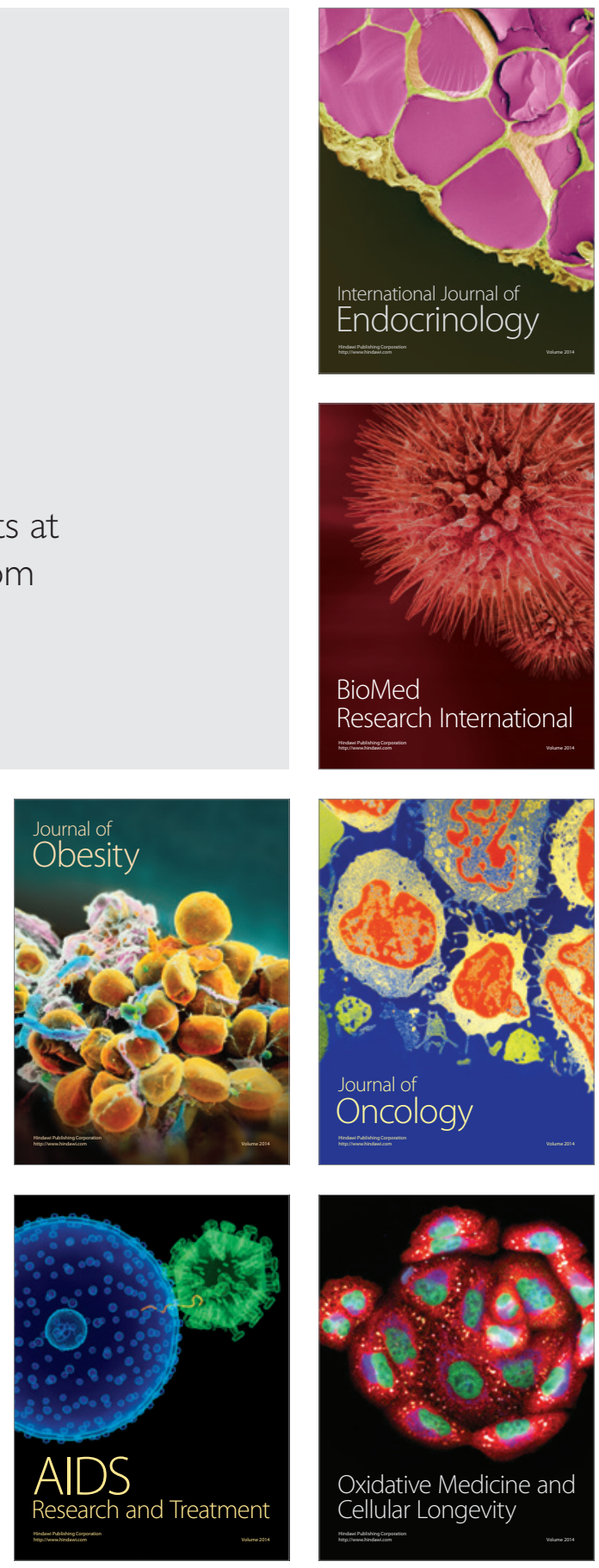